\title{
The study of Fluid Sloshing in a Tank-Fluid System
}

\author{
Kamila Kotrasova ${ }^{1}$ \\ ${ }^{1}$ Institute of Structural Engineering, Civil Engineering Faculty, Technical University of Košice
}

\begin{abstract}
Liquid storage reservoirs are used to store a variety of liquids. This paper deals with the behavior of a fluid under horizontal harmonic motion of a tank. The theoretical background of seismic analysis of the dynamic actions of the fluid in a container - impulsive and convective (sloshing) pressure - is considered. The behavior of the fluid under horizontal harmonic motion of tanks was observed experimentally and tested by numerical simulation using the finite element method (FEM) and the volume of fluid (VOF) method. The first natural frequency, the shape of fluid domain, maximums of wave and pressure were observed, analyzed and compared.
\end{abstract}

Keywords - Acceleration, experiment, fluid, harmonic motion, pressure, tank, wave.

\section{INTRODUCTION}

Large-capacity ground-supported tanks are used to store a variety of liquids. Seismic event is certainly one of the most critical external events regarding safety of industrial plants, as demonstrated by recent earthquakes. If industrial facilities store large amounts of hazardous materials (e.g., petroleum, chemicals, liquefied natural gas, chemical and radioactive waste), accidental scenarios as fire, explosion or toxic dispersion may be triggered, thus possibly involving working people within the installation, population living in close surrounding or in urban area where the industrial installation is located. Liquid storage tanks are considered essential lifeline structures. Satisfactory performance of tanks during strong ground shaking is crucial for modern facilities. Tanks that were inadequately designed or detailed have suffered extensive damage during past earthquakes [1], [4]-[7], [18]. The knowledge of pressures acting on the walls and bottom of containers during an earthquake as well as frequency properties of tank-fluid systems are fundamental for a good analysis and design of earthquake-resistant structures/facilities tanks [2], [8]-[13].

\section{TANK-FLUID SYSTEM}

For rectangular tanks whose walls can be considered as rigid, the hydrodynamic pressure can be obtained from the solution of Laplace's equation for horizontal excitation. The total hydrodynamic pressure is given by the sum of an impulsive and convective contribution by using the absolute summation rule [19]:

$$
p_{H D w}=p_{H D i w}+p_{H D c w} .
$$

A rectangular container with walls having horizontal acceleration $\ddot{u}_{o}$ in the $x$-direction (see Fig. 1a) is considered [2], [18]. Due to the acceleration $\ddot{u}_{o}$, unknown pressures are generated on the walls of the tank. The tank has depth $H$, length $2 L$, and unit thickness. It is obvious that the behavior of the fluid is similar to the case which would be obtained if the horizontal component of the fluid velocity $\dot{u}$ were independent of the $y$-coordinate. That situation looks like as if the fluid were constrained by thin, massless, vertical membranes that are free to move in the $x$-direction; the distance between adjacent membranes is $d x$ (Fig. 1b).

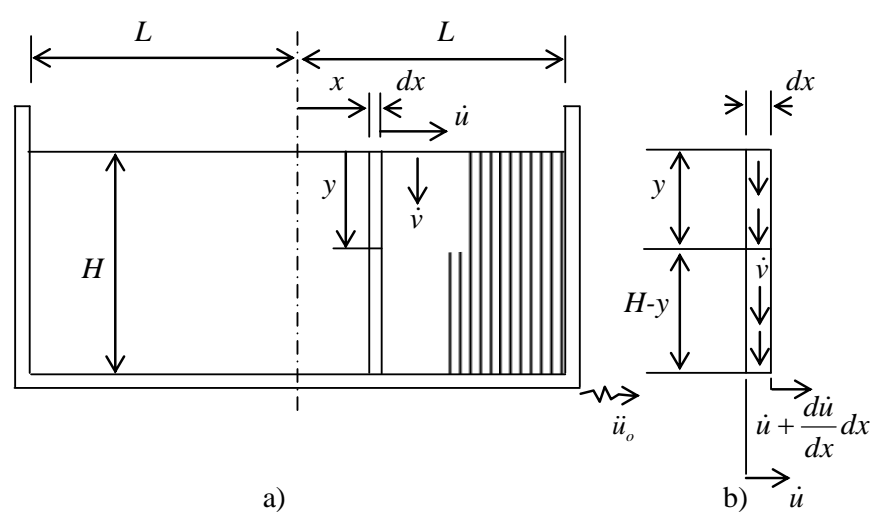

Fig. 1. Rectangular tank-fluid system (impulsive action).

In the case the walls of the container are under known acceleration, the membranes accelerate proportional to the fluid, while, at the same time, the fluid squeezes vertically along membranes $y$-direction.

As shown in Fig. 1b, since the fluid is restrained between two adjacent membranes, the vertical velocity $\dot{v}$ is dependent on the horizontal velocity $\dot{u}$ according to (2):

$$
\dot{v}=(H-y) \frac{d \dot{u}}{d x} \text {. }
$$

This is an equation specifying the constraint on the fluid flow. As the fluid is considered incompressible, it follows that the acceleration $\ddot{v}$ is proportional to the velocity $\dot{v}$ and the acceleration $\ddot{u}$ is proportional to the velocity $\dot{u}$, and the pressure in the fluid between two membranes is given by the standard hydrodynamic equation (3):

$$
\frac{\partial p}{\partial y}=-\rho \ddot{v},
$$

where $\rho$ is density of the fluid.

Total horizontal force on one membrane is

$$
P=\int_{o}^{H} p d y .
$$

These tree equations may be writtten as follows:

$$
\begin{aligned}
& \dot{v}=(H-y) \frac{d \dot{u}}{d x}, \\
& p=-\rho \int_{0}^{y}(H-y) \frac{d \ddot{u}}{d x} d y=-\rho H^{2}\left(\frac{y}{H}-\frac{1}{2}\left(\frac{y}{H}\right)^{2}\right) \frac{d \ddot{u}}{d x},
\end{aligned}
$$




$$
F=-\rho H^{2} \int_{0}^{H}\left(\frac{y}{H}-\frac{1}{2}\left(\frac{y}{H}\right)^{2}\right) \frac{d \ddot{u}}{d x} d y=-\rho \frac{H^{3}}{3} \frac{d \ddot{u}}{d x} .
$$

The velocity is thus solved when the velocity $\dot{u}$ is known.

The kinetic energy of the fluid is

$$
W_{k}=\int_{-L 0}^{+L H} \int_{0} \frac{1}{2} \rho\left(\dot{u}^{2}+\dot{v}^{2}\right) d x d y
$$

and the potential energy of the fluid is zero. Hamilton's principle states that

$$
\delta \int_{t_{1}}^{t_{2}}\left(W_{k}-W_{p}\right) d t=0 .
$$

Let us now derive the equation in a more straightforward fashion. The slice of the fluid shown in Fig. 1b will be accelerated in the $x$-direction if the pressures on the two faces differ. The equation of motion is

$$
\frac{d^{2} \dot{u}}{d x^{2}}-\frac{3}{H^{2}} \dot{u}=0 \text {. }
$$

The acceleration $\ddot{u}_{o}$ thus produces an increase in the pressure on one wall and a decrease in the pressure on the other wall:

$$
p_{w}=\rho \ddot{u}_{0} H\left(\frac{y}{H}-\frac{1}{2}\left(\frac{y}{H}\right)^{2}\right) \sqrt{3} \tanh \sqrt{3} \frac{L}{H} .
$$

In dependence on $\xi=z / H$, where distance $z$ is the distance (height) from the bottom of the tank to the free surface of the liquid $z=H-y$, the hydrodynamic pressures on the wall are given:

$$
p_{H D i w}\left(\frac{z}{H}\right)=\rho \ddot{u}_{0} H \frac{\sqrt{3}}{2}\left(1-\left(\frac{z}{H}\right)^{2}\right) \tanh \sqrt{3} \frac{L}{H} .
$$

Hydrodynamic impulse pressures are as well given by

$$
p_{\text {HDiw }}(\xi)=C_{i w}(\xi) \rho H A_{g}(t)
$$

where the free-field motion of the ground is represented by the $A_{g}(t)$, and $\rho$ is mass density of the liquid.

The distribution of hydrodynamic pressures on the wall of tank $p_{\text {HDiw }}(\xi)$ along the height of wall is given by (11), where the function $C_{i w}(\xi)(12)$ is shown in Fig. 2 in dependence on the tank's "parameter slenderness $\gamma$ '. The function $C_{i w}(\xi)$ presents the functions of partitions of the pressures on the wall for $\xi=0$ (i.e., at the wall of the tank) at the bottom of the tank and for $\xi=1$ (i.e., at the wall of the tank) at the free surface. Tank's "parameter slenderness" is given by relation $\gamma=H / R$, where $H$ is the height of filling of the fluid in the container and $L$ is half of the width of the container:

$$
C_{i w}(\xi)=\frac{\sqrt{3}}{2}\left(1-\xi^{2}\right) \tanh \sqrt{3} \frac{L}{H} .
$$

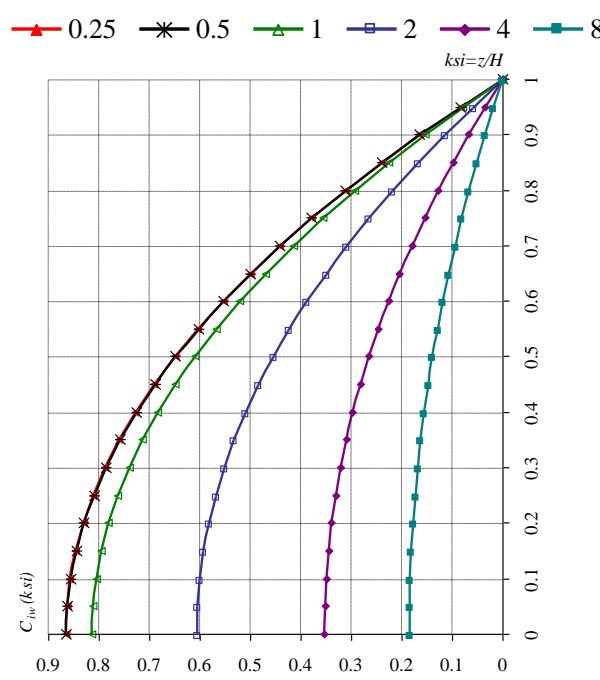

Fig. 2. Functions $C_{i w}(\xi)$ of partitions of the impulse pressures on the wall of the tank in dependence on the parameter of slendness $\gamma$ of the tank.

The effect of impulsive pressures is to excite the fluid into oscilation. In order to examine the fundamental mode of vibration, the fluid to be constrained between the rigid membranes that are free to rotate (as shown in Fig. 3) is considered. The constraint is described by the following equations:

$$
\begin{aligned}
& \dot{u}=\frac{L^{2}-x^{2}}{2} \frac{d \dot{\theta}}{d y}, \\
& \dot{v}=\dot{\theta} z .
\end{aligned}
$$

The pressure in the fluid is given by

$\frac{\partial p}{\partial x}=-\rho \ddot{u}$.

The hydrodynamic pressures are given by

$$
p_{w}=\left(\rho \frac{L^{3}}{3} \sqrt{\frac{5}{2}} \frac{\cosh \sqrt{\frac{5}{2}} \frac{x}{L}}{\sinh \sqrt{\frac{5}{2}} \frac{H}{L}}\right) \omega^{2} \theta_{0} \sin \omega t .
$$

In dependence on $\xi=z / H$, where distance $z$ is the distance (height) from the bottom of the tank to the free surface of the liquid $z=y$, the convective hydrodynamic pressure is given by a summation of modal terms (sloshing modes), each one having a different variation with time:

$$
p_{H D c w n}(\xi)=\sum_{n=1}^{\infty} Q_{c w n}(\xi) \rho L A_{n}\left(f_{c n}\right) \text {. }
$$

As for a rectangular container, the dominant contribution is the fundamental mode, that is:

$$
p_{H D c w 1}(\xi)=Q_{c w 1}(\xi) \rho L A_{1}\left(f_{c 1}\right),
$$

where the free-field motion of the ground is here represented by the peak value of $A_{l}(t)$ that is the acceleration response function of a simple oscillator having the frequency of the first mode, the appropriate value of the damping, and subjected to an input acceleration $A_{g}(t) ; \rho$ is mass density of the liquid. The distribution hydrodynamic pressures on the wall of the tank $p_{H D C \text { M }}(\xi)$ along the height of the wall are given by (18), where 
the function $Q_{c w 1}(\xi)$ (19) is represented in Fig. 4 in dependence on the tank's parameter "slenderness $\gamma$ ". The function $Q_{c w 1}(\xi)$ presents the function of partitions of the pressures on the wall for $\xi=0$ (i.e., at the wall of the tank) at the bottom of the tank and for $\xi=1$ (i.e., at the wall of the tank) at the free surface. The tank's parameter "slenderness" is given by relation $\gamma=H / R$, where $H$ is the height of filling of the fluid in the tank and $L$ is half of the width of the container:

$$
Q_{c w 1}(\xi)=0,833 \frac{\cosh \left(\xi \frac{1}{2} \sqrt{\frac{5}{2}} \frac{H}{L}\right)}{\cosh \left(\frac{1}{2} \sqrt{\frac{5}{2}} \frac{H}{L}\right)} .
$$

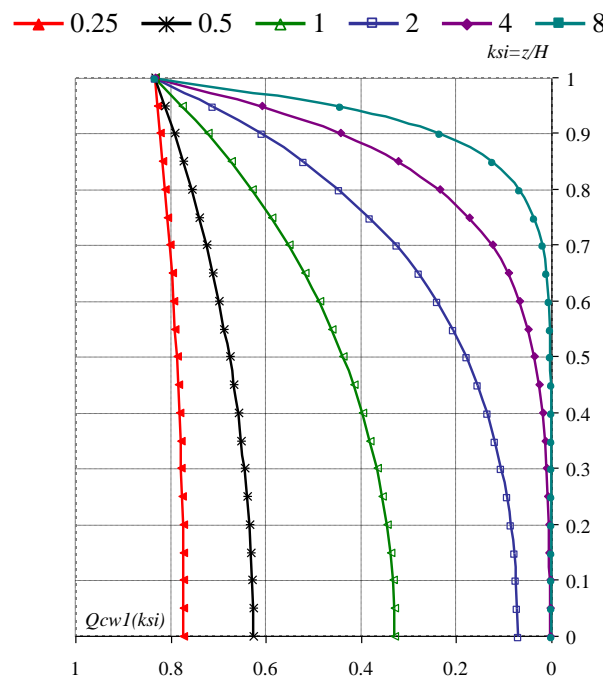

Fig. 4. Functions $Q_{c w 1}(\xi)$ of partitions of the impulse pressures on the wall of the tank in dependence on the parameter of slendness $\gamma$ of the tank.

The equation of the motion of a slice of the fluid is

$$
\int_{-l}^{+l} \frac{\partial p}{\partial y} d y x d x=-\rho \frac{\left(2 L^{3}\right)}{12} \ddot{\theta} d y .
$$

The solution of (20), with the boundary conditions appropriate to the problem, is for sinusoidal oscillations:

$$
\theta=\theta_{0} \frac{\sinh \sqrt{\frac{5}{2}} \frac{y}{L}}{\sinh \sqrt{\frac{5}{2}} \frac{H}{L}} \sin \omega t .
$$

This specifies the oscillation of the fluid. To determine the natural frequency of vibration, the maximum kinetic energy, $W_{K}$, is equated to the maximum potential energy, $W_{P}$ :

$$
\begin{aligned}
& W_{K}=\int_{0}^{h} \int_{-l}^{+l} \frac{1}{2} \rho\left(u^{2}+v^{2}\right) \omega^{2} \sin ^{2} \omega t d x d y, \\
& W_{P}=\int_{-l}^{+l} \frac{1}{2} \rho g x^{2} \sin \omega t d x .
\end{aligned}
$$

That gives

$$
\omega^{2}=\frac{g}{L} \sqrt{\frac{5}{2}} \tanh \sqrt{\frac{5}{2}} \frac{H}{L} .
$$

The circular frequencies are then for the $\mathrm{n}^{\text {th }}$ mode:

$$
\omega_{n}^{2}=\frac{g}{L} n \sqrt{\frac{5}{2}} \tanh n \sqrt{\frac{5}{2}} \frac{H}{L} .
$$

An exact expression is given also by Graham and Rodriguez:

$$
\omega_{n}^{2}=\frac{g}{L} n \frac{\pi}{2} \tanh n \frac{\pi}{2} \frac{H}{L} .
$$

The difference between $\frac{\pi}{2}=1.570796$ in (24), (25) and $\sqrt{\frac{5}{2}}=1.581139$ in $(26)$ give 0.010343 , it is $0.658 \%$.

\section{THE EXPERIMENT}

A glass rectangular tank was used in the experiment. The glass rectangular tank was filled with water by using small quantities of potassium permanganate $\left(2 \mathrm{KMnO}_{4}\right)$. The tank's inner ground parameters were $192 \mathrm{~mm} \times 392 \mathrm{~mm}$, and inner height was $242 \mathrm{~mm}$. The height of water filling in the container was $150 \mathrm{~mm}$. The tank was excited by a horizontal harmonious motion of various frequencies with amplitudes of $5 \mathrm{~mm}$ and $10 \mathrm{~mm}$ in the direction of tank's length $-392 \mathrm{~mm}$ (see Figs 5 and 6), [3], [16], [17], [21].

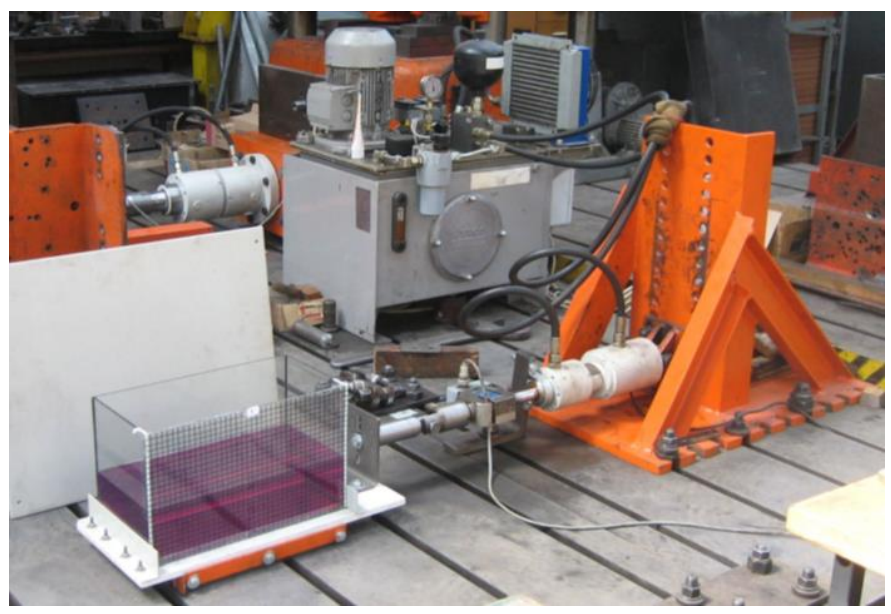

Fig. 5. View of the experimental workstation

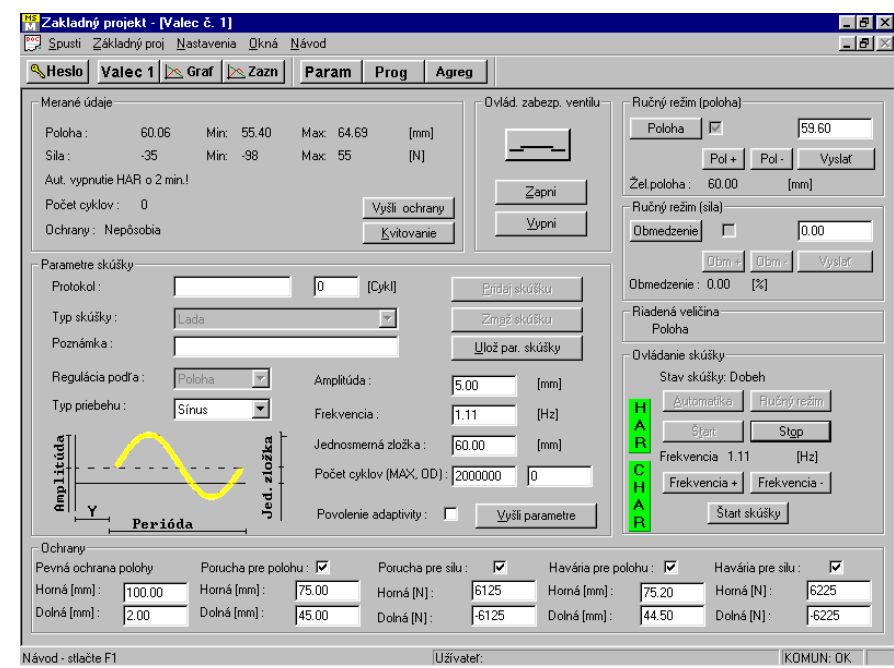

Fig. 6. Wiev of the PC control screen. 


\section{RESUlTS, DisCUSION, AND CONCLUSION}

The maximum wave of fluid for $150 \mathrm{~mm}$ fluid filling (water) in tank could be $92 \mathrm{~mm}$ from free surface. It was expected first natural frequency would be $1.295 \mathrm{~Hz}$ (by Housner) or $1.289 \mathrm{~Hz}$ by (Graham and Rodriguez). Fig. 7 presents the maximum waves for $150-\mathrm{mm}$ filling of water in the tank from the experiment by various exciting frequencies with 5-mm (red square) and 10-mm (blue circle) amplitudes. The maximum height of the fluid wave for $150-\mathrm{mm}$ filling of water in the tank was $90 \mathrm{~mm}$ from the free surface for exciting $1.22 \mathrm{~Hz}$ with a $10-\mathrm{mm}$ amplitude; the blue arrow depicts sloshing out of water in case for $50 \mathrm{~mm}$ amplitude by exciting frequency $1.2 \mathrm{~Hz}$.

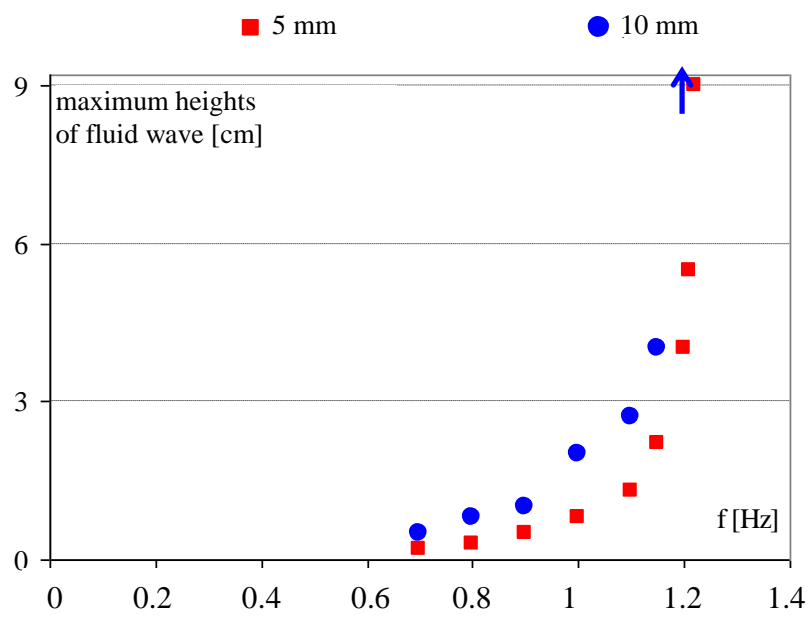

Fig. 7. Maximum wave in [cm] for $150-\mathrm{mm}$ fluid filling of the tank by various exciting with amplitudes 5-mm and 10-mm depending on frekvencies $[\mathrm{Hz}]$.

Figs 8 and 9 show:

- maximum wave $(\mathrm{cm})$ by various exciting frequencies with 5-mm amplitude depending on acceleration (Fig. 8),

- maximum wave $(\mathrm{cm})$ by various exciting frequencies with 10-mm amplitude depending on acceleration (Fig. 9).

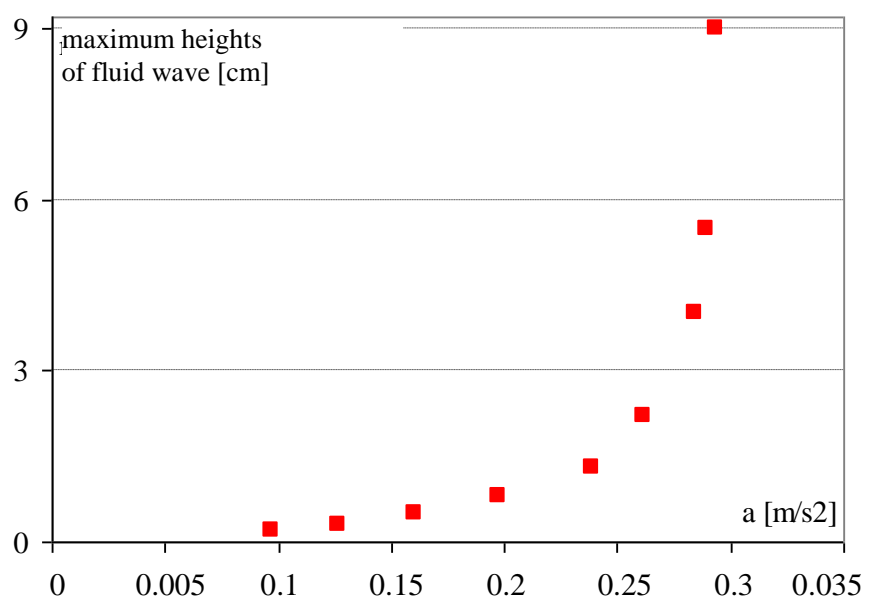

Fig. 8. Maximum wave in [cm] for 150-mm fluid filling of the tank by various exciting with amplitude 5-mm depending on acceleration $\left[\mathrm{m} / \mathrm{s}^{-2}\right]$.

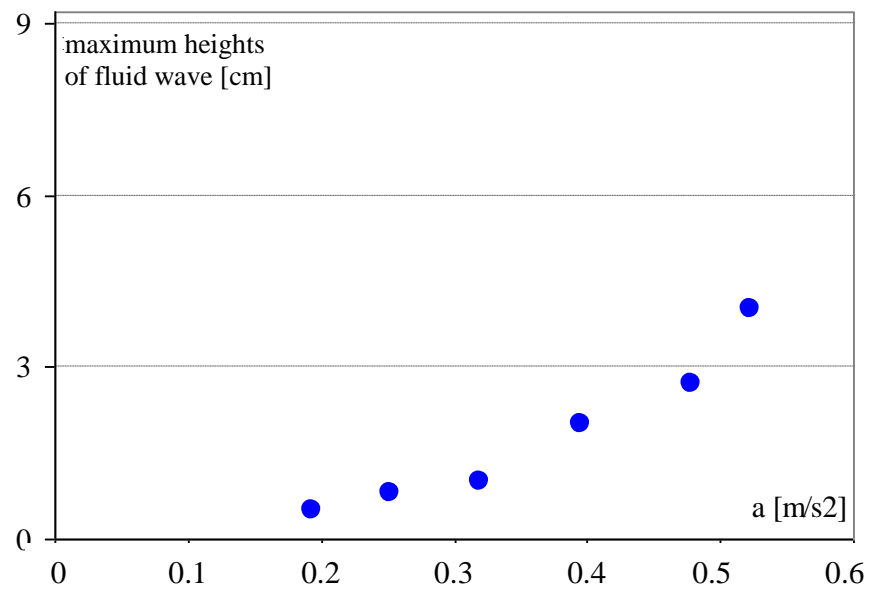

Fig. 9. Maximum wave in [cm] for $150-\mathrm{mm}$ fluid filling of the tank by various exciting with amplitude $10-\mathrm{mm}$ depending on acceleration $\left[\mathrm{m} / \mathrm{s}^{-2}\right]$.

The natural frequencies of fluid in container from our experimentwere calculated by analytical solution, eq. (25), see Fig. 10.

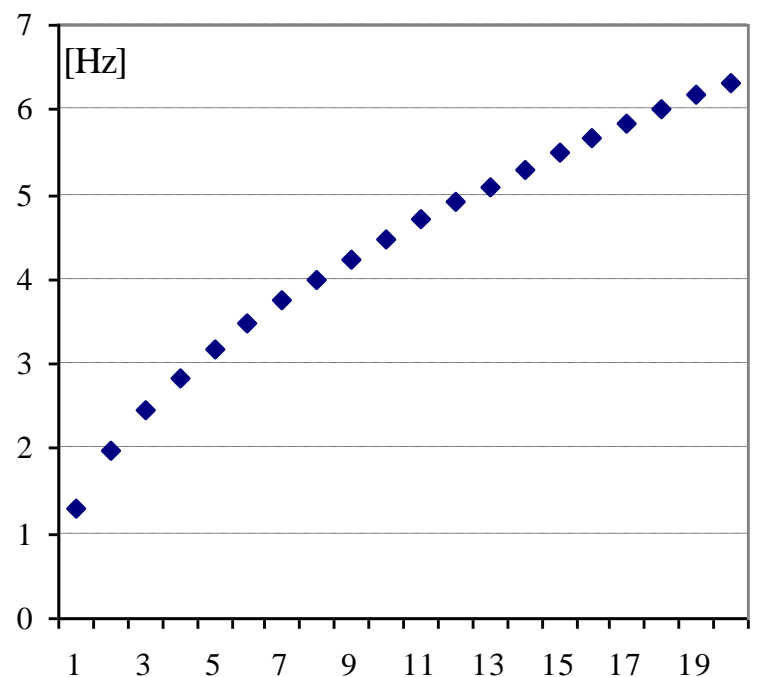

Fig. 10. The natural frequencies of the fluid for $150-\mathrm{mm}$ fluid filling of the tank-fluid system.

Comparing of first natural frequency of fluid in container obtained by measurement from our experiment and by calculating using analytical solutions eq. (24) or (25) and eq. (26) was documented in Table 1.

TABLE I

COMPARISON OF THE FIRST NATURAL FREQUENCY

\begin{tabular}{|c|c|c|}
\hline \multirow{2}{*}{$\begin{array}{l}\text { Analytical } \\
\text { solution }\end{array}$} & by Housner & $1.295 \mathrm{~Hz}$ \\
\hline & $\begin{array}{c}\text { by Graham } \\
\text { and Rodriguez }\end{array}$ & $1.289 \mathrm{~Hz}$ \\
\hline \multirow{2}{*}{ Experiment } & $\begin{array}{l}\text { by exciting amplitude } \\
5 \mathrm{~mm}\end{array}$ & $1.22 \mathrm{~Hz}$ \\
\hline & $\begin{array}{c}\text { by exciting amplitude } \\
10 \mathrm{~mm}\end{array}$ & $\begin{array}{c}1.2 \mathrm{~Hz} \\
\text { (sloshing out) }\end{array}$ \\
\hline
\end{tabular}


The experiment was the base for numerical simulations. The model of fluid filled tank in under horizontal harmonic motion was tested. Moving of free surface without sloshing was watched. The tank with water filling $150 \mathrm{~mm}$, that exited frequency $f=1 \mathrm{~Hz}$ and amplitude $50 \mathrm{~mm}$ was considered. The immediate deflection was given by eq. 27 ,

$$
x=x_{0} \cdot \sin (2 \pi f t),
$$

where $x_{0}=0.005 \mathrm{~m}$, exited frequency was $f=1 \mathrm{~Hz}$, and water filling was $150 \mathrm{~mm}$.

The aim of the modeling of this phenomenon is to consistently achieve the maximum water level so that it is consistent with the results of our experiment. The dynamic time-history response of open-top rectangular liquid storage tanks was performed by application of the volume-of-fluid (VOF) method using software Fluent [14], [17], [22], [23].

The shapes of fluid domain and the maximum heights of wave in the experiment and from numerical simulation using the Fluent software were compared in Fig. 11 and Fig. 12, respectively [14], [18], [19].

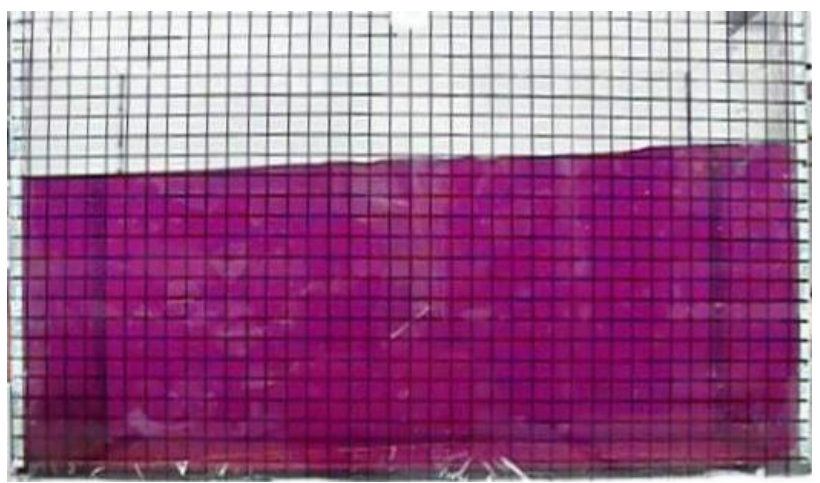

Fig. 11. shapes of the free surface of the fluid and the maximum wave in the experiment.

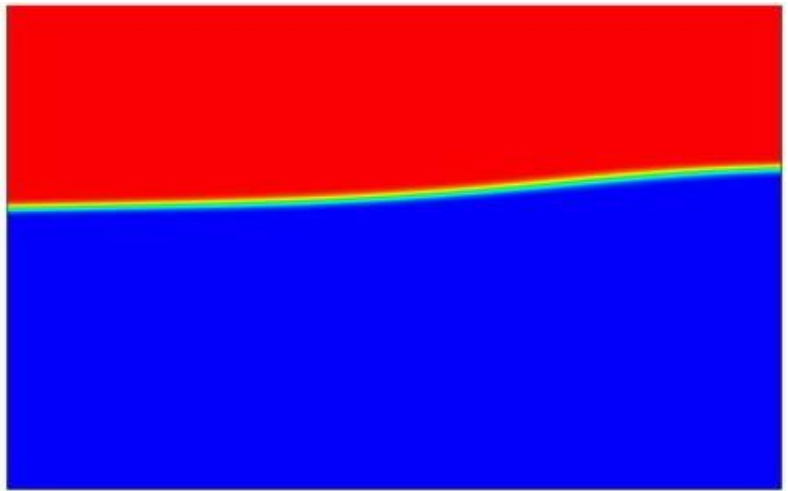

Fig. 12. Shape of the fluid domain and the maximum wave in numerical simulation.

Figs 13 and 14 show:

- time-dependent response of the displacement together with the velocity of the fluid at the point of right top the edge of the fluid on free surface (Fig. 13),

- time-dependent response of the displacement together with the pressure of the fluid at point right down the edge of fluid (Fig. 14).

The controled hydrostatic pressure on the bottom of the container was calculated by the analytical result:

$p=\rho \cdot g \cdot h=1000 \cdot 9.81 \cdot 0.15=1471.5 \mathrm{~Pa}$.

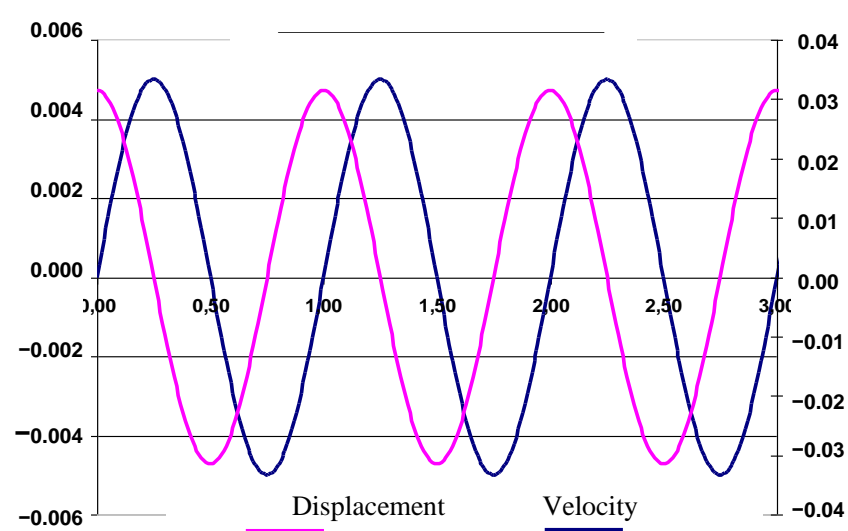

Fig. 13. Time-dependent response of vertical displacement in $[\mathrm{m}]$ and velocity of the fluid in $\left[\mathrm{ms}^{-1}\right]$.

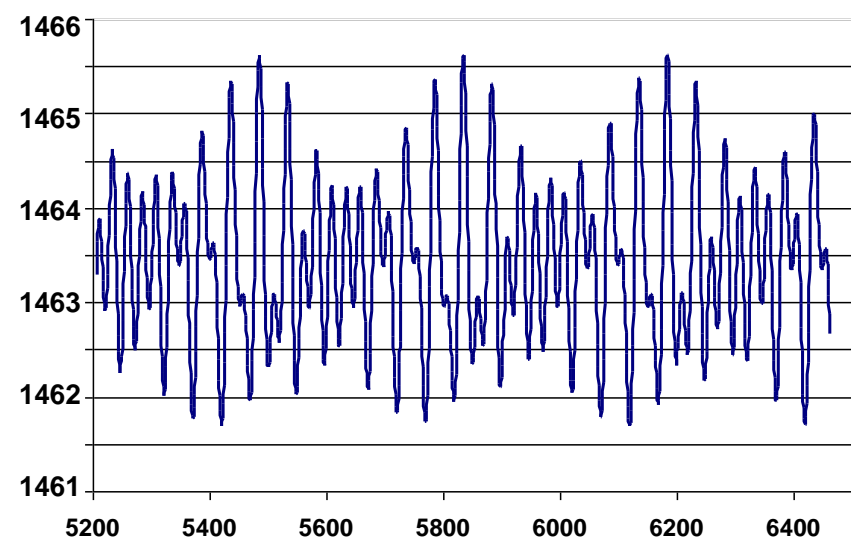

Fig. 14. Time-dependent response of fluid pressure on the bottom of the tank in $[\mathrm{Pa}]$.

Dynamic time-history response of rectangular liquid storage tanks was performed by using the finite element method (FEM) using Adina software.

Fig. 15 demonstrates the shape of the fluid domain and pressure of the fluid in time $t=2.275 \mathrm{~s}$.

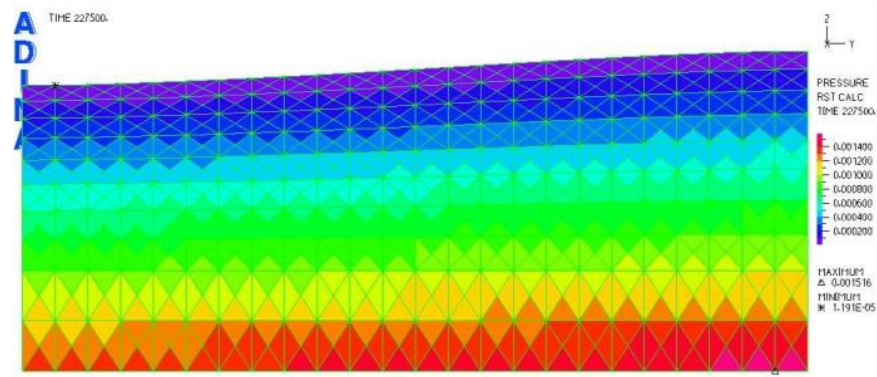

Fig. 15. Shape of the fluid domain and pressure of the fluid in time $t=2.275 \mathrm{~s}$.

\section{ACKNOWLEDGMENT}

This work was supported by the project VEGA 1/0477/15 "Numerical analysis and modeling of interactive problems in multilayered composite structural members". 


\section{REFERENCES}

[1] A. Di Carluccio, G. Fabbrocino, E. Salzano, G. Manfredi, "Analysis of pressurized horizontal vessels under seismic excitation," in 18th The World Conference on Earthquake Engineering (ICSV18). Oct 12-17, 2008, Beijing, China.

[2] Housner, G., W.: "Earthquake pressures on fluid containers", California institute of technology, Pasadena, California, 1954

[3] N. Jendzelovsky, L. Balaz, "Modeling of a gravel base under the cylindrical tank," Advanced Material Research, vol. 969, 2014, pp. 249252, ISSN 1022-6680. http://dx.doi.org/10.4028/www.scientific.net/AMR.969.249

[4] N. Jendzelovsky, J., Sumec, "Stress - strain fields of the reinforced water tower under seismic loads," 9th int scientific conf. VSU' 2009. 4 5 June, 2009, Sofia, Bulgaria, vol. 1. Sofia: "L. Karavelov" civil engineering higher school, 2009. P. I76-I-80. ISBN 978-954-331-023-4.

[5] E. Juhasova, J. Bencat, V. Kristofovic, S. Kolcun, "Expected seismic response of steel water tank," in 12th European Conf. on Earthquake Engineering, Paper reference 595, London 2002.

[6] J. Kralik, "Dynamic analysis of soil-fluid-tank interaction due to earthquake even," in Dynamika tuhých a deformovatelných těles 2012 . sborník přednášek z 10. mezinárodni konference: 10.-12. ř́ina 2012, Ústí n. L., ČR, ISBN: 978-80-7414-500-0.

[7] J. Kralik, J. Kralik, jr., "Probability assessment of analysis of high-rise buildings seismic resistance," Advanced Materials Research, vol. 712 715, 2013, pp. 929-936. http://dx.doi.org/10.4028/www.scientific.net/AMR.712-715.929

[8] K. Kotrasova, "Sloshing of Liquid in Rectangular Tank," Advanced Materials Research. no. 969 (2014), pp. 320-323. ISBN 978303835147-4, ISSN 1662-8985. http://dx.doi.org/10.4028/www.scientific.net/AMR.969.320

[9] K. Kotrasova, I. Grajciar, "Analýza hydrodynamických tlakov kvapaliny na steny pravouhlej nádrže so štíhlost'ou $\gamma=1$ počas zemetrasenia," Civil and evironmental engineering. Roč. 5, č. 2 (2009), s. 79-87. ISSN 1336-5835.

[10] K. Kotrasova, I. Grajciar, "Dynamic Analysis of Liquid Storage Cylindrical Tanks Due to Earthquake," Advanced Materials Research. no. 969 (2014), pp. 119-124. ISBN 978-303835147-4, ISSN 1662-8985. http://dx.doi.org/10.4028/www.scientific.net/AMR.969.119

[11] K. Kotrasova, I. Grajciar, E. Kormanikova, "Dynamic Time-History Response of cylindrical tank considering fluid - structure interaction due to earthquake," Applied Mechanics and Materials. no. 617 (2014), pp. 66-69, ISSN 1660-9336. http://dx.doi.org/10.4028/www.scientific.net/AMM.617.66

[12] K. Kotrasova, E. Kormanikova, "A Case Study on the Seismic Behavior of Tanks Considering Soil-Structure-Fluid Interaction," J. of vibration engineering \& technologies, vol. 3, Issue 3, pp. 315-330. ISSN 2321 3558 .

[13] K. Kotrasova, E. Kormanikova, "Hydrodynamic Analysis of Fluid Effect in Rigid Rectangular Tank Due to Harmonic Motion," Key Engineering Materials, vol. 635, 2015, pp. 147-150. ISBN 978303835344-7 http://dx.doi.org/10.4028/www.scientific.net/KEM.635.147

[14] K. Kotrasova, D. Sojcak, "Možnost' riešenia interakcie kvapaliny s nádobou pri harmonickom pohybe," Civil and evironmental engineering, Roč. 5, č. 2 (2009), s. 72-78. ISSN 1336-5835.

[15] I. S. Leoveanu, K. Kotrasova, E. Kormanikova, "Use Computer Fluid Dynamics in the Process of Forced Flow Filling, Earthquake and Dam Breaking Disaster of Waste Water Reservoirs," Structural and Physical Aspects of Civil Engineering, 2013 s. 1-8. ISBN 978-80-553-1488-4.

[16] J. Melcer, "Dynamic response of a bridge due to moving loads," J. of Vibrational Engineering and Technologies, vibration engineering \& technologies. ISSN 2321-3558, vol. 3, Issue 2, Jan. 1 2015, pp. 199-209.

[17] J. Sumec, N. Jendželovský, "Reinforced concrete water tank response under a seismic load," Roczniki inżynierii budowlanej, no. 8 (2008), pp. 71-76 ISSN: 1505-8425.

[18] V. Michalcova et al. "Numerical and experimental investigations of air flow turbulence characteristics in the wind tunnel contraction," Applied Mechanics and Materials. vol. 617 (2014), pp. 275-279 ISSN: 1022-6680 http://dx.doi.org/10.4028/www.scientific.net/AMM.617.275

[19] B. Taraba, Z Michalec, V. MichalcovÁ, T. Blejchar, M Bojko, M Kozubkova, "CFD simulations of the effect of wind on the spontaneous heating of coal stockpiles," Fuel. 2014, vol. 118, pp. 107112, ISSN 0016-2361, http://dx.doi.org/10.1016/j.fuel.2013.10.064.

[20] K. Tvrda, J. Dicky, "Topological Optimization of Girders," J. of Civil Engineering. ISSN: 1336-9024.
[21] K. Tvrda, "Optimization and safety desing of the foundation plate," in Modelováni v mechanice 2015: Proceedings of scientific conference. Ostrava, May 28th-29th, 2015, pp. 1-10. ISBN: 978-80-248-3756-7.

[22] M. Žmindak, I. Grajciar, "Simulation of the aquaplane problem," Computers and Structures, vol. 64, Issue 5-6, Sept. 1997, pp. 11551164. http://dx.doi.org/10.1016/S0045-7949(97)00024-2

[23] EN 1998-4: 2006 Eurocode 8, Design of structures for earthquake resistance, Part 4: Silos, Tanks and Pipelines, CEN, Brussels, 2006.

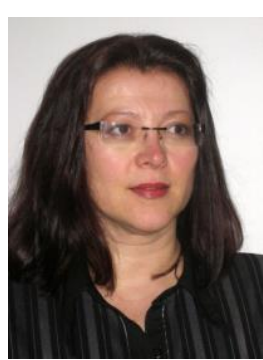

Kamila Kotrasova graduated from the Civil Engineering Faculty of the Technical University of Košice. in 1983. The major field of study was building construction. From 1983, she was an engineer-designer at Region Civil Compasny in Spišská Nová Ves. From 1984, she is a teacher at the Technical University of Košice. She received PhD degree in study program Applied Mechanics in 2009 from Faculty of Mechanical Engineering at Technical University of Košice. The title of $\mathrm{PhD}$ Thesis was "Dynamic interaction of tanks with fluid and soil by seismic exitacion". She received Associate Professor degree in study program Theory and Design of Engineering in 2015 from Faculty of Civil Engineering at Technical University of Košice. The title of Associate Professor Thesis was "Interaction of fluid with solid of tank by earthquake".

Current Position: teacher at the Technical University of Košice. The research topics: seismic design of liquid storage ground-supported tanks, interaction problems of fluid, solid and subsoil.

She is a member of the Slovak Society for Mechanics, SAS, and Central European Association for Computational Mechanics, and theauthor of more than 198 scientific papers published in scientific journals and presented at international scientific conferences.

E-mail: kamila.kotrasova@tuke.sk 